\title{
Responses of compound ascidian larvae to haloclines
}

\author{
Elsa Vázquez*, Craig M. Young \\ Department of Larval Ecology, Harbor Branch Oceanographic Institution, 5600 U.S. Hwy 1 North, Ft. Pierce, Florida 34946, USA
}

\begin{abstract}
Larval swimming behavior in response to sharp laboratory haloclines was studied in 4 species of subtropical colonial ascidians: Eudistoma hepaticum, Eudistoma olivaceum, Ecteinascidia turbinata and Polyandrocarpa zorritensis. Larvae were observed as they swam upward from seawater of high salinity ( 33 or $28 \mathrm{ppt}$ ) into a layer of lower salinity. The vertical movements of larvae in columns with haloclines were compared with movements of larvae in unstratified control columns. Dilute seawater at 10 and $16 \mathrm{ppt}$ acted as a barrier to tadpoles of all species swimming toward the surface. Seawater at 22 ppt also halted upward progression in all species except Eudistoma hepaticum. Seawater of 26 ppt was passed without difficulty by the larvae of all species. However, most larvae (with the exception of Eudistoma olivaceum) sank or swam out of $26 \mathrm{ppt}$ sea water as soon as they arrived at the airwater interface, whereas larvae in 33 ppt control columns remained at the surface for significantly longer periods of time. There were interspecific differences in the larval responses, some of which could explain differences in the distances that various species penetrate into coastal lagoons. However, salinity was not a robust explanation for overall distributional patterns. The observed responses to haloclines could help explain how larvae are retained near parental habitats in the mouths of estuaries.
\end{abstract}

KEY WORDS: Ascidian - Larval behavior - Halocline Salinity - Distribution

\section{INTRODUCTION}

Salinity influences numerous physical parameters important to marine invertebrates, including osmolality, relative proportions of solutes, absorption and saturation of dissolved gasses, density, viscosity, surface tension, absorption of radiation, and transmission of sound (Kinne 1971). In estuaries, fjords, lagoons and other coastal ecosystems, low salinity water originating from streams, rivers, or terrestrial runoff often overlies a deeper layer of water with higher salinity to form a halocline. The persistence of such stratified water columns varies regionally. For example, in the Kattegat region of Scandinavia, which has little tidal mixing and receives a consistent input of brackish water from the Baltic Sea and oceanic water from the Norwegian Sea, the halocline is virtually permanent, whereas in many coastal lagoons, haloclines may be ephemeral phe-

\footnotetext{
- Present address: Dpto Bioloxía Animal. Facultade de Bioloxía, Universidade de Santiago, E-15706 Santiago de Compostela, Spain.E-mail: eotero@uvigo.es
}

nomena present only under particular tidal regimes and rainfall conditions.

In the absence of turbulent mixing, a detrital particle or other object moving passively upward or downward through the water column comes to rest at that level where its density is the same as that of the surrounding water. In haloclines, water density changes rapidly over a short vertical distance, so particles of many different sizes and densities concentrate there. Thus, enhanced concentrations of phytoplankton, detritus and bacteria are known to occur at or near the halocline layer (e.g. Nielsen et al. 1993), and the chlorophyll maximum is often located at or near this depth (Southward \& Barrett 1983). Actively swimming organisms including holoplankton (Williams 1985), meroplankton (Hansen 1951) and ichthyoplankton (Lasker 1975, Kendall \& Naplin 1981) are often found near haloclines, presumably because of greater feeding opportunities

High population densities of consumers probably make haloclines particularly dangerous places for prey organisms and this may be one reason why some species seem to avoid them. Hansen (1951) found that vertical distributions of planktonic animals varied in a 
stratified water column as a function of species; Southward \& Barrett (1.983) noted that a relatively small proportion of species they studied off southwest England actually concentrated at the halocline layer. Haloclines may sometimes separate organisms instead of concentrating them. For example, Williams (1985) found that the copepods Calanus finmarchicus and C. helgolandicus reside on separate sides of the seasonal thermocline in the Celtic Sea, thereby minimizing interspecific competition. Likewise, a plankton community characterized by the presence of the chaetognath Sagitta elegans occurred in cold water below the thermocline in the English Channel, whereas a community characterized by the presence of $S$. setosa occured mostly in the warmer waters above the thermocline (Southward \& Barrett 1983). This community separation persisted by day and night, but was not complete, as some species from deep water migrated through the thermocline at night. The number of such migrators depended on the density differences between water masses. More species migrated when there was a $3^{\circ} \mathrm{C}$ temperature difference than when there was a $6^{\circ} \mathrm{C}$ difference (Southward \& Barrett 1983). Several studies have suggested that larvae of benthic invertebrates are physically unable to pass through the halocline and are therefore 'captive' in the water mass in which they were spawned (Banse 1964, Angel 1968, Fransz et al. 1984).

Because residence in a halocline may be either advantageous or disadvantageous to planktonic organisms, it is not surprising that behavioral responses to haloclines vary among taxa. Harder (1968) showed experimentally that some species pass haloclines readily while others are limited by them. He further showed that some of the species concentrating there selected the halocline habitat behaviorally. In some cases, a slight density discontinuity has no effect on the movements of planktonic larvae, while a steeper gradient truncates the normal pattern of vertical migration (Scarratt \& Raine 1967, Roberts 1971, McConnaughey \& Sulkin 1984). The ability to detect and avoid waters of reduced salinity by larvae has been demonstrated experimentally for larvae of numerous animals that are motile during the adult stage: Mercenaria mercenaria trochophores (Turner \& George 1955), Phyllodoce maculata trochophores (Lyster 1965), some copepoda and the zoeal instars of Pisidia longicornis (Lance 1962), zoea I of Homarus americanus (Scarratt \& Raine 1967) and Pagurus longicarpus larvae (Roberts 1971). Only one study (C. M. Young \& I. Svane unpubl.), on tadpoles of Ascidiella aspersa, shows that larvae of sessile animals are capable of responding to haloclines, thereby avoiding salinity conditions where metamorphosis and settlement would be unsuccessful.
Tolerance to salinity variation often varies ontogenetically; in many cases, early life history stages are less tolerant of wide salinity variation than adults. This is exemplified by the ascidian Ciona intestinalis, whose larvae are more tolerant of low salinities than zygotes, and whose adults are even more tolerant (Dybern 1967) Similar observations have been made with polychaetes (Lyster 1965), brachyuran crabs, molluscs (Kinne 1966) and other ascidians (Young \& Svane unpubl.). The physiological tolerances and behavioral responses of larvae to waters of various salinities are particularly interesting as these may determine the water bodies where recruitment ultimately occurs. In cases where larvae of benthic animals concentrate at haloclines, there should be a higher recruitment density at the depth where the halocline intersects the sea floor. This has been demonstrated for larvae of solitary ascidians, Ascidiella aspersa and A. scabra, living in Gullmar Fjord, Sweden (Young \& Svane unpubi.). Sessile animals like tunicates cannot avoid salinity changes after settlement, so larval processes may be critical. In species such as C. intestinalis, which can tolerate low salinities, popuiations may be ninainitnatained during low salinity periods until salinity conditions are again suitable for spawning and for embryonic and larval survival (Dybern 1967).

In the present paper, we investigated the ability of compound ascidian larvae to respond to salinity gradients of varying steepness, choosing for comparative purposes larvae of some ascidians that penetrate into coastal lagoons of varying salinity and others that are apparently restricted to full oceanic salinities. This study represents the initial portion of a larger study on the physiological responses of various life history stages to low salinity conditions. We also provide new information on the spawning times of 4 species of compound ascidians.

\section{MATERIALS AND METHODS}

The experiments were carried out with the larvae of 4 species of compound ascidians: 2 species in the family Polycitoridae, Eudistoma hepaticum (Van Name, 1921) and Eudistoma olivaceum (Van Name, 1902); 1 species in the family Perophoridae, Ecteinascidia turbinata Herdman, 1880; and 1 species in the family Styelidae, Polyandrocarpa zorritensis (Van Name, 1931).

Adult colonies were collected at Jim Island, a small island near Ft. Pierce Inlet in the Indian River Lagoon, Florida, USA, between April and June 1994. Polyandrocarpa zorritinsis and Eudistoma hepaticum were collected from a vertical wall between 0 and $1.5 \mathrm{~m}$ depth, and Ecteinascidia turbinata and Eudistoma oli- 
vaceum were collected from mangrove Rhizophora mangle roots between 0 and $1 \mathrm{~m}$ depth. The water temperature ranged from $25^{\circ} \mathrm{C}$ in April to $30^{\circ} \mathrm{C}$ in June and the salinity from $34 \mathrm{ppt}$ in April to $31 \mathrm{ppt}$ in June. The maximum annual temperature was $32.4^{\circ} \mathrm{C}$ in August and the minimum $18.5^{\circ} \mathrm{C}$ in December, and the maximum salinity $35 \mathrm{ppt}$ in June and the minimum 21 ppt in August. A complete description of the site and of the mangrove-associated epifauna has been provided by Bingham (1990).

Experimental haloclines were established in plexiglass cylinders $7 \mathrm{~cm}$ in diameter and $22 \mathrm{~cm}$ tall, marked off in $1 \mathrm{~cm}$ segments and covered with a styrofoam cap (Fig. 1). Two $3 \mathrm{~mm}$ diameter glass tubes, one $26 \mathrm{~cm}$ long and the other $15 \mathrm{~cm}$ long, penetrated the cap and extended into the water column near the middle of the cylinder. The long tube was used to introduce larvae $3 \mathrm{~cm}$ above the bottom of the cylinder and to sample water from well below the halocline. The short tube opened $17 \mathrm{~cm}$ above the bottom and was used to sample water just above the halocline. These tubes remained in place during the experiments so as not to disturb the water column. Larvae were introduced and water was sampled by inserting long pasteur pipettes into the tubes. Salinities above and below the halocline were determined with an American Optical temperature compensated refractometer of $1 \mathrm{ppt}$ resolution. Because we did not determine salinities with temperature-corrected conductivity measurements using the practical salinity scale (Millero 1993), we have elected to express salinity values in the traditional way, as parts per thousand (ppt).

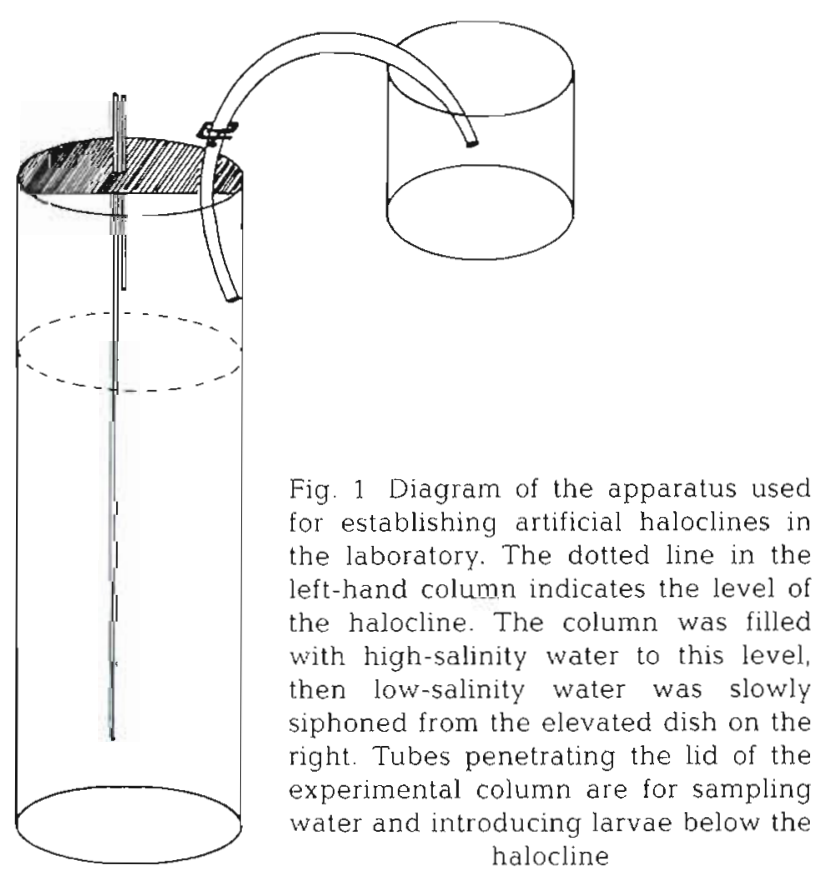

In most experiments, salinity gradients had $33 \mathrm{ppt}$ seawater in the deep portion of the column and water of some lower salinity at the surface. We also ran experiments with 2 species using 28 ppt as the deep seawater. To set up an abrupt salinity gradient, the cylinder was first filled with filtered 33 or $28 \mathrm{ppt}$ sea water to a depth of $16 \mathrm{~cm}$. Water of lower salinity was then siphoned very slowly through a thin plastic tube to the top of this layer, controlling flow with a hose clamp (Fig. 1). Low salinity water was added until the water surface was $19 \mathrm{~cm}$ above the bottom. A total of 4 salinities were used for the upper layers: 10, 16, 22 and 26 ppt. The low salinity water was made by mixing full-salinity seawater with aerated distilled water. Preliminary tests in which the low salinity water was mixed with dyes indicated that mixing occurred only about $3 \mathrm{~mm}$ above and $3 \mathrm{~mm}$ below the halocline. The entire salinity gradient therefore occupied a vertical distance of only $6 \mathrm{~mm}$ and was centered at a height $16 \mathrm{~cm}$ above the bottom. A second column identical to the first but filled with filtered $33 \mathrm{ppt}$ sea water to the full depth of $19 \mathrm{~cm}$ served as an unstratified control.

After an artificial halocline was established, we waited $15 \mathrm{~min}$, then sampled water from the 2 layers to determine if the desired stratification had been achieved. If salinity measurements indicated that too much mixing had occurred, we discarded the water and made another attempt.

Water was maintained at a constant temperature of $24 \pm 1^{\circ} \mathrm{C}$ in all experimental columns. In most animals, salinity tolerance is not influenced appreciably by temperature within the thermal range normally encountered in the habitat (Kinne 1971). Larvae sometimes came from adults in aquaria that were maintained at a slightly lower temperature. In such cases, they were acclimated for $15 \mathrm{~min}$ in a container of $24^{\circ} \mathrm{C}$ water at 33 or $28 \mathrm{ppt}$, as appropriate, before introducing them into the experimental vessels. We did not attempt to control or measure the photic environment; all experiments were run on a laboratory bench near a north-facing window, though the time of day varied by species as a function of larval release time (Table 1). None of the

Table 1 Larval release times following light shock for the 4 compound ascidian species studied. Ascidian colonies were adapted to darkness for at least $12 \mathrm{~h}$, then moved in to the light at $7: 30 \mathrm{~h}$

\begin{tabular}{|lcc|}
\hline Species & $\begin{array}{c}\text { Range of } \\
\text { release } \\
\text { times (h) }\end{array}$ & $\begin{array}{c}\text { Time of } \\
\text { maximum } \\
\text { release (h) }\end{array}$ \\
\hline Eudistoma hepaticum & $10: 30-17: 00$ & $13: 00$ \\
Eudistoma olvaceum & $9: 30-13: 00$ & $11: 00$ \\
Ecteinascidia turbinata & $9: 30-18: 00$ & $9: 30-15: 00$ \\
Polyandrocarpa zorritensis & $8: 30-11: 00$ & $8: 30-11: 00$ \\
\hline
\end{tabular}


experiments were run in direct sunlight. The room lights were on during all the experiments.

Adult ascidian colonies were maintained in dark, aerated aquaria overnight, then moved outside into direct sunlight at 7:30 $\mathrm{h}$ to trigger release of larvae. We did not isolate individual colonies; in every case, larvae used in experiments came from a mixture of several adult colonies. Tadpoles were collected with a pasteur pipette and stockpiled in dishes of 33 ppt filtered seawater. Larvae were between 5 and 30 min old when first introduced into the columns. The experimental protocol was as follows. An individual larva was injected into the bottom of the column using a long pasteur pipette inserted through the long tube. Larvae were introduced into both stratified and unstratified columns within a few seconds of each other so the 2 treatments could be run under identical light regimes. The larvae could be followed with the naked eye due to their bright colours and large sizes (larger than $5 \mathrm{~mm}$ ); Eudistoma hepaticum larvae are white, E. olivaceum larvae are yellow-green, Ecteinascidia turbinata larvae are bright orange and Polyandrocarpa zorrintesis larvae are brown.

Ascidian larvae generally exhibit a hop-and-sink swimming pattern in which upward swimming is probably a response to gravity (Svane \& Young 1989). We recorded the maximum height attained by a larva during each bout of upward swimming and made careful notes of other aspects of swimming behavior Observations were continued until larvae either stopped swimming for several minutes or attached to the inside of the column. We observed no significant changes in the swimming behaviors of larvae between early and later observations, so all observations were combined for plotting and analysis. Observations were made while the larvae were being released so the range of observation times was the same as the release times shown in Table 1 . The number of larvae used and the number of individual observations in each experiment are shown in Table 2.
We ran each salinity treatment (with its associated control column) twice for each species over a 1 or $2 \mathrm{~d}$ period. This gave us 2 replicate runs per salinity treatment and 8 control replicates per species. The 2 -tailed Kolmogorov-Smirnov (K-S) 2-sample test was used to determine, for both the stratified and unstratified columns, whether the distributions of vertical distances attained in the 2 replicate runs came from populations with the same statistical distribution. When there were no significant differences between replicates of the hacloclines as well as the control columns, we pooled data from the 2 runs into a single data set for analysis. The treatments could then be compared directly with a 1 -tailed K-S test (Sokal \& Rohlf 1981). Where pooling was not justified, we ran separate tests comparing treatments within each run. In one species (Eudistoma olivaceum), we found it necessary to discard 1 complete run because the tadpoles were lethargic and seldom swam high enough in the water column io encounter the halocline. We characterized species differences in swimming behavior by running parametric analyses of variance with the replicate runs from the controi coiumns 18 ol 4 i epicates per species).

\section{RESULTS}

\section{Behavior of larvae in unstratified full-salinity sea water}

Larvae of all 4 species demonstrated the same general swimming behavior in unstratified control columns at $33 \mathrm{ppt}$. Tadpoles swam from the bottom to the surface (Figs. 2-5) in 5 to $10 \mathrm{~s}$, where they stayed, constantly swimming, for a variable period of time ranging from 20 to $180 \mathrm{~s}$. Eventually, they always stopped swimming and sank or swam toward the bottom. Tadpoles of Eudistoma hepaticum often swam downward actively (Table 3); the other species nearly always sank passively. In cases when tadpoles did not

Table 2. Number of larvae used in each experimental treatment and total number of observations in each treatment. ' $\mathrm{C}$ ' are control (unstratified) columns run simultaneously with ' $\mathrm{P}$ ' (stratified) columns. For example, P10 is a stratified (halocline) column having $33 \mathrm{ppt}$ water on the bottom and $10 \mathrm{ppt}$ water on the top. $\mathrm{C} 10$, the control column for the P10 experiment, has only 33 ppt water

\begin{tabular}{|c|c|c|c|c|c|c|c|c|}
\hline \multirow{2}{*}{ Treatment } & \multicolumn{2}{|c|}{ Eudistoma hepaticum } & \multicolumn{2}{|c|}{ Eudistoma olivaceum } & \multicolumn{2}{|c|}{ Ecteinascidia turbinata } & \multicolumn{2}{|c|}{ Polyandrocarpa zorritensis } \\
\hline & $\begin{array}{l}\text { No. of } \\
\text { larvae }\end{array}$ & $\begin{array}{l}\text { No. of } \\
\text { obs. }\end{array}$ & $\begin{array}{l}\text { No. of } \\
\text { larvae }\end{array}$ & $\begin{array}{l}\text { No. of } \\
\text { obs. }\end{array}$ & $\begin{array}{l}\text { No. of } \\
\text { larvae }\end{array}$ & $\begin{array}{c}\text { No. of } \\
\text { obs. }\end{array}$ & $\begin{array}{l}\text { No. of } \\
\text { larvae }\end{array}$ & $\begin{array}{c}\text { No. of } \\
\text { obs. }\end{array}$ \\
\hline $\mathrm{C} 10$ & 47 & 87 & 32 & 58 & 50 & 98 & 45 & 66 \\
\hline P10 & 47 & 126 & 34 & 93 & 50 & 1.43 & 46 & 102 \\
\hline C16 & 33 & 51 & 28 & 60 & 50 & 98 & 56 & 80 \\
\hline P16 & 35 & 113 & 34 & 126 & 50 & 159 & 56 & 86 \\
\hline $\mathrm{C} 22$ & 30 & 48 & 28 & 60 & 50 & 98 & 47 & 87 \\
\hline P22 & 32 & 72 & 30 & 90 & 50 & 135 & 52 & 116 \\
\hline $\mathrm{C} 26$ & 30 & 48 & 32 & 68 & 50 & 98 & 45 & 78 \\
\hline P26 & 33 & 63 & 35 & 89 & 50 & 101 & 45 & 89 \\
\hline
\end{tabular}


Table 3. Percentage of downward moving larvae that swam actively rather than sinking passively in each experimental treatment. Numbers in parentheses are sample sizes (number of individual larvae observed). Unstratıfied columns were all filled with water of $33 \mathrm{ppt}$ salinity, but are listed next to the stratified treatment with which they were run simultaneously

\begin{tabular}{|c|c|c|c|c|c|c|c|c|}
\hline \multirow[t]{2}{*}{ Species } & \multicolumn{2}{|c|}{$10 \mathrm{ppt}$} & \multicolumn{2}{|c|}{$16 \mathrm{ppt}$} & \multicolumn{2}{|c|}{$22 \mathrm{ppt}$} & \multicolumn{2}{|c|}{$26 \mathrm{ppt}$} \\
\hline & Stratified & Unstrat. & Stratified & Unstrat. & Stratified & Unstrat. & Stratified & Unstrat \\
\hline Eudistoma hepaticum & $15.9(126)$ & $6.9(87)$ & $32.7(113)$ & $0(51)$ & $4.2(72)$ & $0(46)$ & $20.6(63)$ & $0(46)$ \\
\hline Eudistoma olvaceum & $1.9(52)$ & $0(20)$ & $0(53)$ & $0(22)$ & $0(48)$ & $0(22)$ & $0(37)$ & $0(30)$ \\
\hline Ecteinascidia turbinata & $2.1(143)$ & $0(98)$ & $0(159)$ & $0(98)$ & $1.5(135)$ & $0(98)$ & $0(101)$ & $0(98)$ \\
\hline Polyandrocarpa zorritensis & $0(102)$ & $0(57)$ & $0(87)$ & $0(80)$ & $0(90)$ & $0(116)$ & $0(89)$ & $0(78)$ \\
\hline
\end{tabular}

reach the surface, they stopped swimming and sank passively. Sometimes they began swimming up again before reaching the bottom of the column.

Larvae of Eudistoma hepaticum swam upward in broad helices, whose diameters were nearly as large as the diameters of the columns. The other 3 species
A

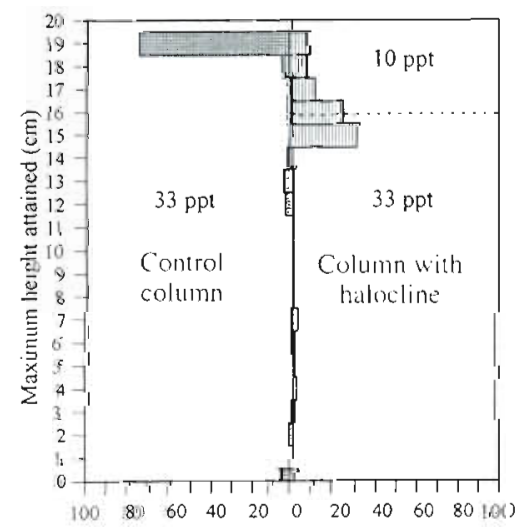

C

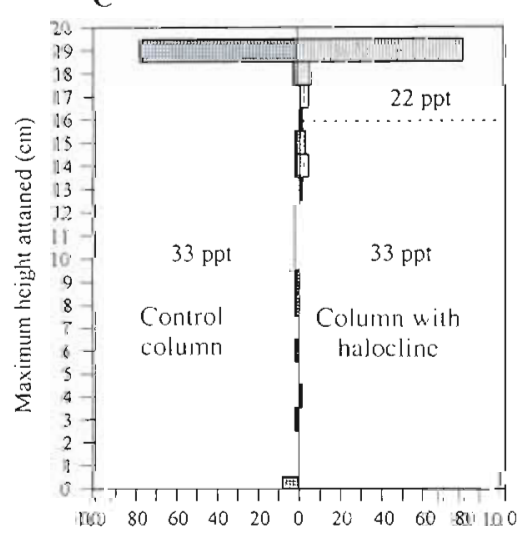

\section{B}

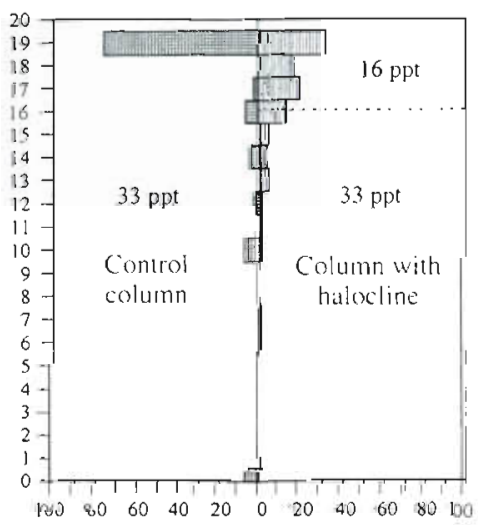

D

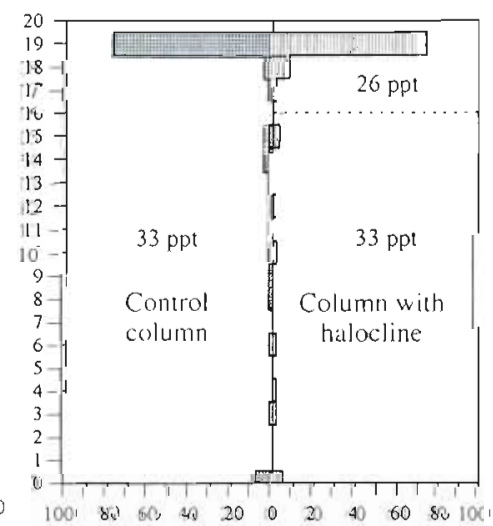

$\%$ of larvae
Fig. 2. Eudistoma hepaticum. Distributions of the maximum heights attained by vertically swimming larvae in unstratified control columns (left side of each graph) and in columns having haloclines with surface waters of 4 different salinities (A-D) (right sides of graphs). Statistical analysis of these data are presented in Tables $3 \& 4$. Data from the 2 analyses are pooled for the plots, but not always for analysis (see text) rotated as they swam, but their helical movements had very small radii, resulting in more or less straight swimming trajectories.

Some larvae didn't swim when they were introduced in the column, but they stayed on the bottom without any movement for several minutes. These are shown on the graphs as ' 0 ' values. Some of these larvae swam toward the surface later.

In unstratified water, the proportion of larvae actually reaching the surface differed significantly ( $p<0.0001)$ among species (Table 4) with larvae of Ecteinascidia turbinata attaining the surface significantly more often than larvae of Eudistoma hepaticum or Polyandrocarpa zorritensis (Tukey HSD a posteriori test; Table 4).

\section{Behavior of larvae in stratified columns with full-salinity bottom water}

For the sake of brevity, we refer hereafter to the stratified columns by the salinity of the surface layer. Except where otherwise noted, all of the stratified columns had a salinity of $33 \mathrm{ppt}$ in the lower layer. Thus, for example, ' 10 ppt' refers to a treatment with $10 \mathrm{ppt}$ salinity overlying 33 ppt sea water.

\section{Eudistoma hepaticum}

There were no significant differences between replicates for the larvae that reached each height in either the stratified column or the control column for any treatment (Table 5), so data were pooled for analysis. The distributions of heights attained by tadpoles differed between stratified and unstratified columns in the 10 and 16 ppt experiments, but not in the 22 or 26 ppt experiments (Table 6). 
Table 4. (A) One-way analysis of variance comparing the proportions of larvae un each species reaching the surface in unstratified 33 ppt columns. Data were arcsin transformed prior to analysis. (B) Tukey ISD pairwise comparison of means in which asterısks denote significant differences between pairs at $\mathrm{p}<0.05$

\begin{tabular}{|c|c|c|c|c|c|c|}
\hline \multicolumn{7}{|l|}{ (A) ANOVA } \\
\hline \multicolumn{2}{|l|}{ Between species } & 3 & 7.197 & 2.99 & 10.76 & 0.0001 \\
\hline \multirow{2}{*}{\multicolumn{2}{|c|}{$\begin{array}{l}\text { Within species } \\
\text { Total }\end{array}$}} & 24 & 5.353 & 2.230 & & \\
\hline & & 27 & 1.255 & & & \\
\hline \multicolumn{7}{|c|}{ (B) Tukey statistic and significance } \\
\hline & Mean & & $\begin{array}{c}\text { Ecteinascidia } \\
\text { turbinata }\end{array}$ & $\begin{array}{l}\text { Eudistoma } \\
\text { hepaticum }\end{array}$ & & $\begin{array}{l}\text { Eudistoma } \\
\text { olivaceum }\end{array}$ \\
\hline E. turbinata & 1.108 & & & & & \\
\hline E. hepaticum & 8.779 & & $4.37^{\bullet}$ & & & \\
\hline E. olivaceum & 8.722 & & 3.65 & 0.09 & & \\
\hline $\begin{array}{c}\text { Polyandrocarpa } \\
\text { zorritensis }\end{array}$ & 6.852 & & $8.02^{\circ}$ & 3.65 & & 2.89 \\
\hline
\end{tabular}

A

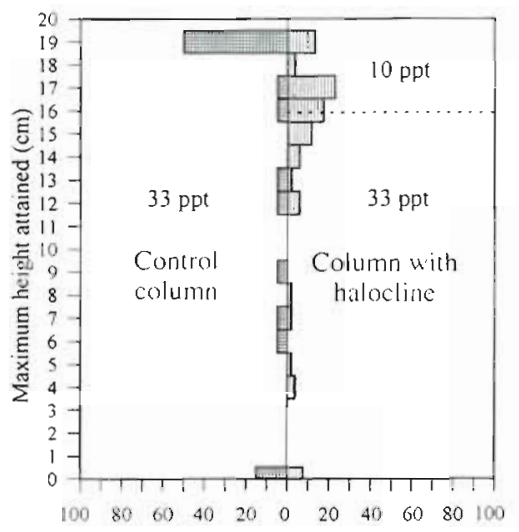

$\mathrm{C}$

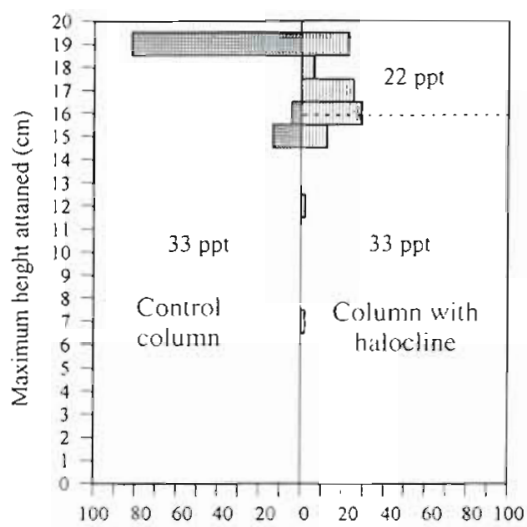

B

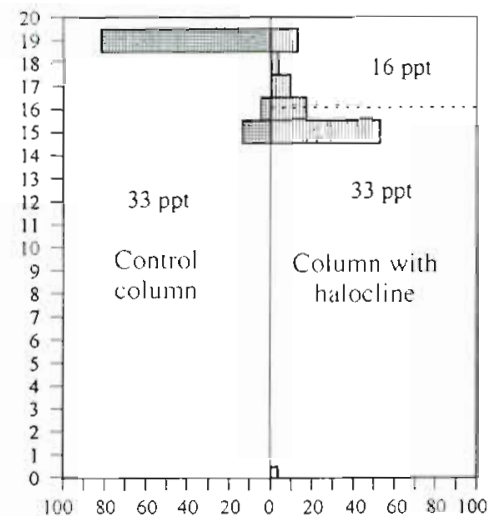

D

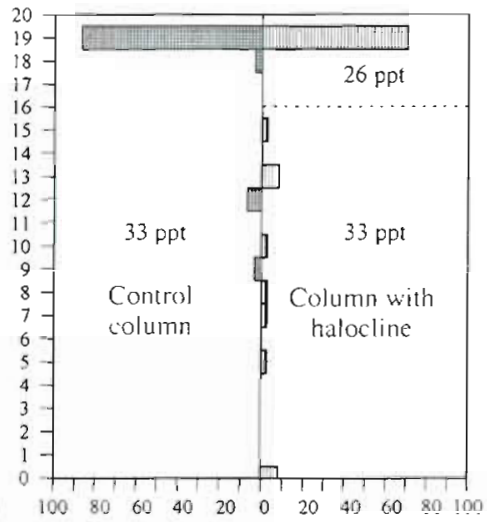

$\%$ of larvae

Fig. 3. Eudistoma olivaceum. Distributions of the maximum heights attained by larvae in stratified and unstratified columns. See Fig. 2 for detailed explanation
In the stratified $10 \mathrm{ppt}$ column, larvae stopped at the level of the halocline (15 to $17 \mathrm{~cm}$ ) in $72.5 \%$ of the observations. Three of these larvae turned and swam downward; the remainder all stopped swimming at the halocline and sank passively until they reached the bottom. Larvae passed through the halocline in $16 \%$ of the observations, but only $9 \%$ reached the surface, sinking passively immediately after reaching the surface (Fig. 6A). By contrast, $100 \%$ of the larvae in the control column that reached the surface (Fig. 2A) continued swimming at the surface for several seconds to several minutes (Fig. 6A).

At $16 \mathrm{ppt}$, larvae passed through the halocline in $68 \%$ of the observations, but only $32 \%$ actuaily reached the surface (Fig. 2B). About $85 \%$ of the larvae reaching the surface sank or swam downward immediately; the remainder swam at the surface ful mure thain $5 \mathrm{~s}$ (Fig. 6A). By contrast, $95 \%$ of the tadpoles arriving at the surface in the control column remained swimming at the surface for a period of $5 \mathrm{~s}$ or more (Fig 6A). There were also subtle behavioral differences between larvae in stratified and unstratified columns at 16 ppt. In the control column, larvae swam directly to the surface but, in the stratified column, those larvae that would eventually penetrate the halocline layer generally swam at the halocline for up to $5 \mathrm{~s}$ before continuing upward. When passing through the low salinity water, they made frequent stops, each of several seconds duration.

Almost all the larvae $(90 \%)$ in the 22 ppt experiment were able to pass through the halocline (Fig. 2C). However, the first time larvae encountered water of lower salinity, they hesitated briefly and moved the tail erratically before continuing upward. A few larvae initially swam down several cm when encountering the halocline, but they invariably turned u.pward again. They swam more slowly above the halocline than below it and generally stopped swimming several times for periods of 1 to $2 \mathrm{~s}$ while swimming through the $4 \mathrm{~cm}$ distance between the halocline and the surface. There appeared to be some behavioral adaptation to the Iow salinity, as larvae seldom dis- 
Table 5. Results of 2-tailed Kolmogorov-Smirnov 2-sample tests $(D)$ comparing the distributions of heights attained by swimming tadpoles between the 2 replicate runs of each treatment. Where between-replicate differences were significant $(" p<0.05 ; " \cdot p<$ 0.01 , pooling was not justified and data from each replicate was analyzed separately for treatment effects

\begin{tabular}{|c|c|c|c|c|c|c|c|c|}
\hline \multirow{2}{*}{ Species } & \multicolumn{2}{|c|}{$10 \mathrm{ppt}$} & \multicolumn{2}{|c|}{$16 \mathrm{ppt}$} & \multicolumn{2}{|c|}{$22 \mathrm{ppt}$} & \multicolumn{2}{|c|}{$26 \mathrm{ppt}$} \\
\hline & Stratified & Unstrat. & Stratified & Unstrat. & Stratified & Unstrat. & Stratified & Unstrat. \\
\hline Eudistoma hepatıcum & 0.21 & 0.09 & 0.21 & 0.25 & 0.20 & 0.15 & 0.12 & 0.15 \\
\hline Eudistoma olivaceum & $0.38^{*}$ & 0.31 & $0.28^{\circ}$ & $0.66^{*}$ & $0.55^{\cdots}$ & $0.66^{*}$ & $0.51 \cdots$ & $0.66^{*}$ \\
\hline Ecteinascidla turbinata & $0.25^{\circ}$ & 0.05 & 0.14 & 0.05 & $0.36^{*}$ & 0.05 & 0.11 & 0.05 \\
\hline Polyandrocarpa zorritensis & 0.20 & $0.37^{\circ}$ & 0.24 & 0.15 & $0.28^{\circ}$ & 0.05 & 0.24 & 0.13 \\
\hline
\end{tabular}

played this hesitation behavior when passing into the halocline on subsequent swimming bouts. Most larvae that had passed through the halocline once passed it the second time without stopping. Of those larvae reaching the surface in the stratified column, $33 \%$ sank immediately, in contrast to the control column, where as only $3 \%$ sank and $97 \%$ continued swimming at the surface for more than $5 \mathrm{~s}$.

At $26 \mathrm{ppt}$, there was no significant statistical difference between the distributions of heights attained in stratified and control columns. Nearly $90 \%$ of larvae reached the surface in both treatments (Fig. 2D). However, we observed the same kinds of behaviors at this salinity as at $22 \mathrm{ppt}$. Of the larvae arriving at the surface, $58 \%$ continued swimming there (Fig. 6A) and the remainder moved downward, $41 \%$ by swimming actively (Table 3) and the remainder by sinking passively

\section{Eudistoma olivaceum}

Larvae used for one run of this experiment were lethargic and appeared unhealthy. Attempts to obtain additional larvae near the end of the reproductive season were unsuccessful so we analyzed only the data from the reliable run. As in Eudistoma hepaticum, there were significant differences in swimming height distributions between unstratified columns and stratified columns at the 3 lowest salinities, but not at the highest salinities (Fig. 3, Table 6). Larvae of this species swam directly upward until reaching either the water surface or the halocline. Downward movement was always by passive sinking, in contrast to the congeneric $E$. hepaticum, which often swam actively downward.
At $10 \mathrm{ppt}$, larvae reached the halocline $(15$ to $17 \mathrm{~cm}$ heights) in $52 \%$ of the observations (Fig. 3A). A total of 7 larvae $(13.5 \%)$ reached the surface and began sinking as soon as they arrived. In all of these instances, the larvae paused for 2 to $5 \mathrm{~s}$ at the level of the halocline on the way up, and also stopped several times in the low salinity water before arriving at the surface. This same general be-
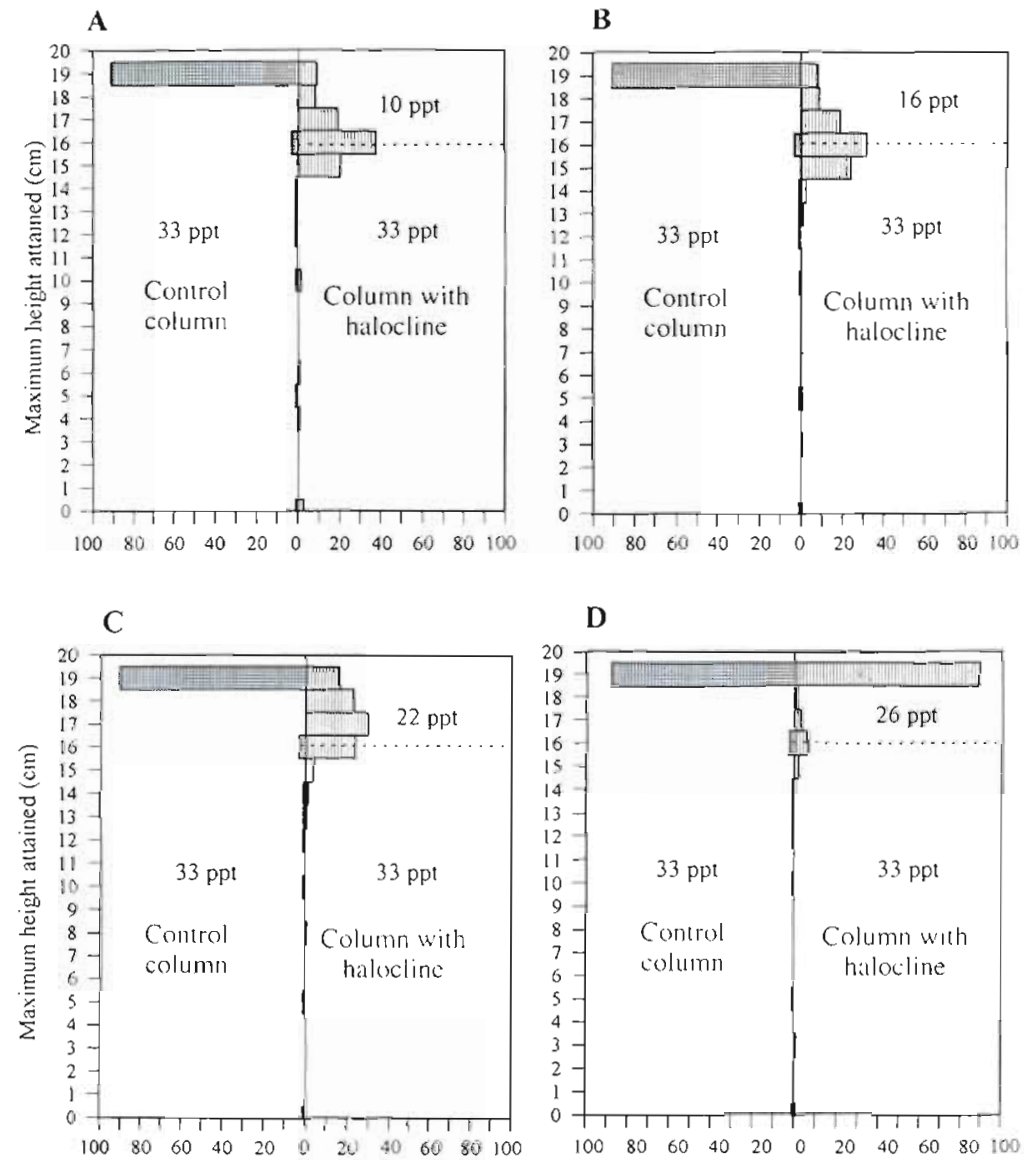

\section{D}

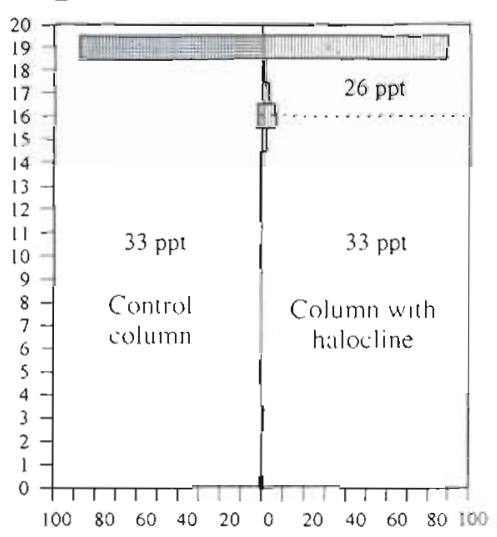

$\%$ of larvae

Fig. 4. Ecteinascidia turbinata. Distributions of the maximum heights attained by larvae in stratified and unstratified columns. See Fig. 2 for detalled explanation 
Table 6. Results of 1-tailed Kolmogorov-Smirnov 2-sample tests $(D)$ comparing the distributions of helghts attained by ascidian larvae in stratified and unstratified columns. Where the 2 replicates $(A, B)$ were not significantly different, they were pooled $(P)$ and only the pooled statistic is given. Where they were significantly different, separate analyses were run. Significance levels:

$$
\cdot p<0.05 ; \cdots p<0.01
$$

\begin{tabular}{|c|c|c|c|c|c|c|c|c|c|c|c|c|}
\hline \multirow[t]{2}{*}{ Species } & \multicolumn{3}{|c|}{$10 \mathrm{ppt}$} & \multicolumn{3}{|c|}{$16 \mathrm{ppt}$} & \multicolumn{3}{|c|}{$22 \mathrm{ppt}$} & \multicolumn{3}{|c|}{$26 \mathrm{ppt}$} \\
\hline & A & B & $\mathrm{P}$ & A & $\mathrm{B}$ & $P$ & A & B & $\mathrm{P}$ & A & $\mathrm{B}$ & $P$ \\
\hline Eudistoma hepaticum & - & - & $0.64 \cdot \cdot$ & - & - & $0.43 \cdots$ & - & - & 0.00 & - & - & 0.02 \\
\hline Eudistoma olivaceum & $0.37^{\circ}$ & - & - & $0.69^{\circ}$ & - & $0.59 \cdot$ & - & - & 0.20 & - & - & - \\
\hline Ecteinascidia turbinata & $0.84^{\cdots}$ & $0.79 \cdots$ & - & - & - & $0.83 \cdots$ & $0.84^{\cdots}$ & $0.63^{*}$ & - & - & - & 0.05 \\
\hline Polyandrocarpa zorritensis & $0.84^{\bullet}$ & $0.79 \cdots$ & - & - & - & $0.83 \cdots$ & $0.84^{*}$ & $0.63^{\cdots}$ & - & - & - & 0.05 \\
\hline
\end{tabular}

havior was observed in the 16 and 22 ppt treatments. However, at $16 \mathrm{ppt}$, the majority of larvae stopped near the bottom of the halocline at $15 \mathrm{~cm}$ height (Fig. 3B) whereas at $22 \mathrm{ppt}$, larvae penetrated to a higher level of the halocline (Fig. 3C). $73 \%$ of the larvae reaching the surface sank without further swimming and the remainder swam from 5 to 30 s before sinking.
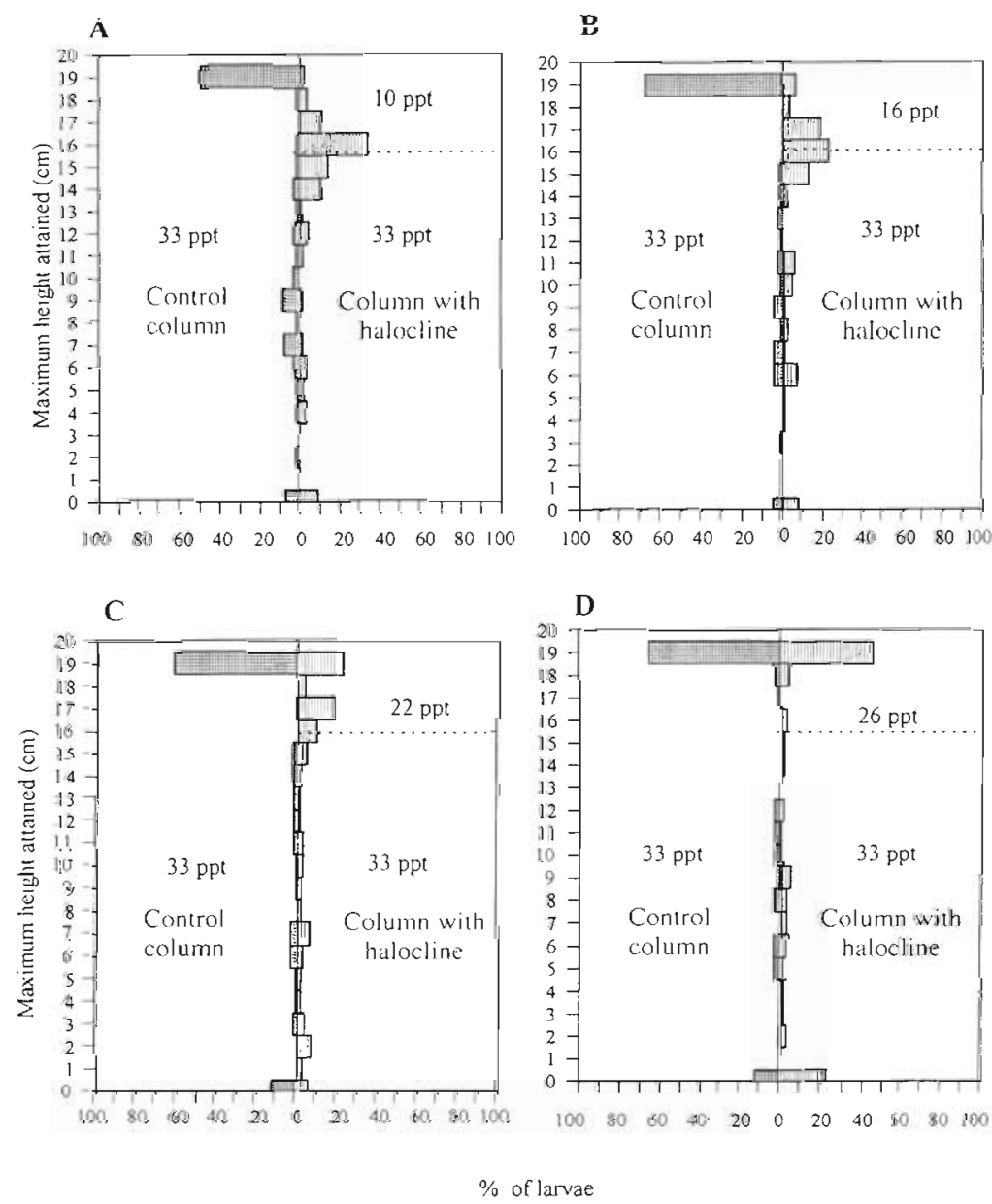

Fig. 5. Polyandrocarpa zorritensis Distributions of the maximum heights attained by larvae in stratified and unstratified columns. See Fig. 2 for detailed explanation
At 26 ppt, more than $70 \%$ of the larvae reached the surface and the halocline had no effect whatsoever on the distributions of heights attained (Fig. 3D). In contrast to lower salinity treatments, all larvae arriving at the surface continued swimming there for 20 to $30 \mathrm{~s}$ before sinking to the bottom (Fig. 6B). Nevertheless, we observed the same behavioral differences between stratified and unstratified columns as in the lower salinities; larvae generally hesitated at the level of the halociine before swimming through it.

\section{Ecteinascidia turbinata}

There were significant differences between replicate stratified columns at 10 and 22 ppt (Table 5), so the replicates were analyzed separately in these experiments. Significant differences were found between stratified and unstratified columns in every case at 10 , 16 and 22 ppt (Table 6).

At $10 \mathrm{ppt}$, larvae stopped within $1 \mathrm{~cm}$ of the halocline in $76.92 \%$ of the observations (Fig. 4A), sinking passively. All of the 13 larvae reaching the surface moved down immediately (Fig. 6C), 9 sinking passively and 4 swimming actively downward. When moving into low salinity water, these larvae hesitated at the halocline. The behavior of larvae and the distributions of heights attained were virtually identical at 16 and 10 ppt. In a few cases, larvae encountering the $16 \mathrm{ppt}$ halocline swam downward 2 or $3 \mathrm{~cm}$, then tried to penetrate the halocline again.

At 22 ppt, larvae behaved the same as at lower salinities, but more larvae penetrated into the upper part of the halocline (Fig. 4C). Only $16 \%$ of the larvae reached the surface and of these, $95.5 \%$ 
sank as soon as they touched. The remaining $4.5 \%$ swam at the surface 30 to $60 \mathrm{~s}$ before sinking (Fig. 6C).

There was not a significant difference between stratified and control columns at $26 \mathrm{ppt}_{\text {; }}$ in both treatments, nearly $90 \%$ of larvae reached the surface. However, there was a difference in the number that remained at the surface $100 \%$ in the control column, $20.5 \%$ in the stratified column). Thus, a difference of 4 ppt salinity in the surface water can have a major effect on the vertical distribution of larvae. As at lower salinities, larvae often paused at the halocline and stopped frequently in the low salinity layer when swimming upward.

\section{Polyandrocarpa zorritensis}

There were significant between-replicate differences in the unstratified column at $10 \mathrm{ppt}$ and in the stratified column at 22 ppt (Table 5), so replicates were analyzed separatedly at these salinities. This was the only species demonstrating significant differences $(p<0.01)$ in heights attained with all haloclines tested, including 26 ppt $(p<0.05)$ (Table 6)

At $10 \mathrm{ppt}$, the majority of larvae stopped and sank within $1 \mathrm{~cm}$ of the halocline (Fig. 5A). Only 2 larvae passed through the discontinuity layer and reached the surface. Both of these became inactive immediately and remained inactive, apparently having died. Numerous larvae swam to the surface in the control column (Fig. 5A) and the latter always swam at the surface for an extended period of time (Fig. 6D). The distributions and behaviors of larvae at 16 and $22 \mathrm{ppt}$ were virtually identical to those at $10 \mathrm{ppt}$ (Fig. 5B, C) except that larvae penetrated further beyond the halocline at 22 ppt ( $22 \%$ of larvae actually arrived at the surface). Some of the larvae sinking from the surface resumed upward swimming when they encountered high salinity water at $16 \mathrm{~cm}$ helght Larvae of Polyandrocarpa zorritensis demonstrated the same pausing behavior in water above the halocline as larvae of the other species

At $26 \mathrm{ppt}, 45 \%$ of the larvae reached the surface and these did not pause at the halocline on the way up (Fig. 5D). However, there was still a significant difference $(p<0.05)$ (Table 6 ) between stratified and control columns in the percentage of larvae that contunued swimming at the surface (Fig. 6D).
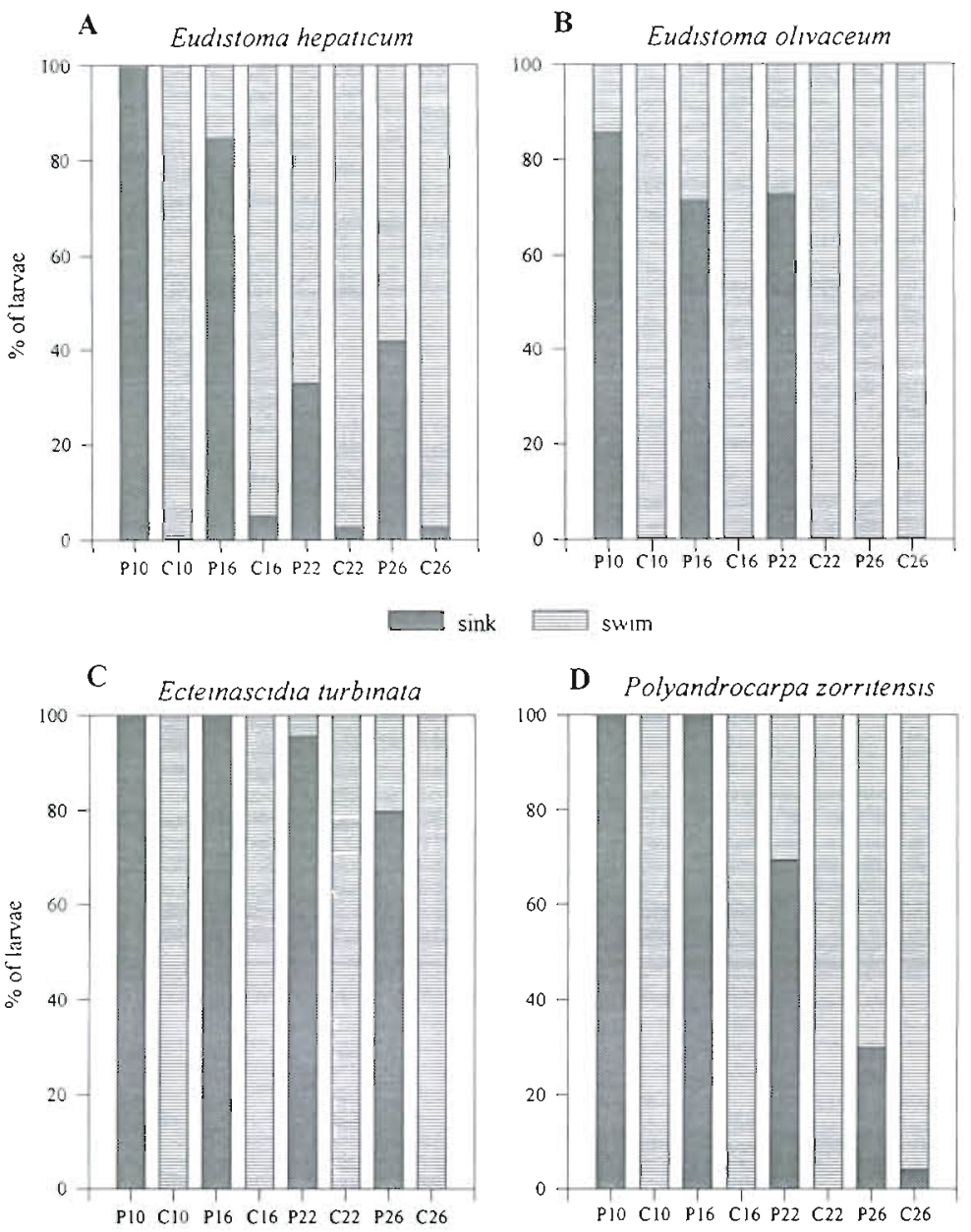

Fig 6 Percentages of larvae armving at the surface in each treatment that continued swimming there for longer than $5 \mathrm{~s}$ ('swim') and that sank or swam downward immedıately after arrival ('sınk') Labels of histogram bars indicate whether the treatment was a control column (C) or halocline column (P) and also the salinity of the surface water in each halochne column

\section{Larval responses to haloclines with low salinity bottom water}

We were interested in knowing if the observed responses to low salinity water above haloclines was caused by the absolute salinity of the surface water or alternatively by the change in salinity that the larvae expenenced as they migrated through the halocline We approached this problem by adapting larvae to 28 ppt seawater, then establishing sharp haloclines using water of this salinity on the bottom. We ran these experiments with 2 species, Polyandrocarpa zorntensis and Ecteinascidia turbinata. Tadpoles of $P$. zorritensis migrated to the halocline much less frequently when originating in 28 ppt bottom water than in 33 ppt bottom water (Fig. 7A). The majority of larvae remained on the bottom without swimming up 

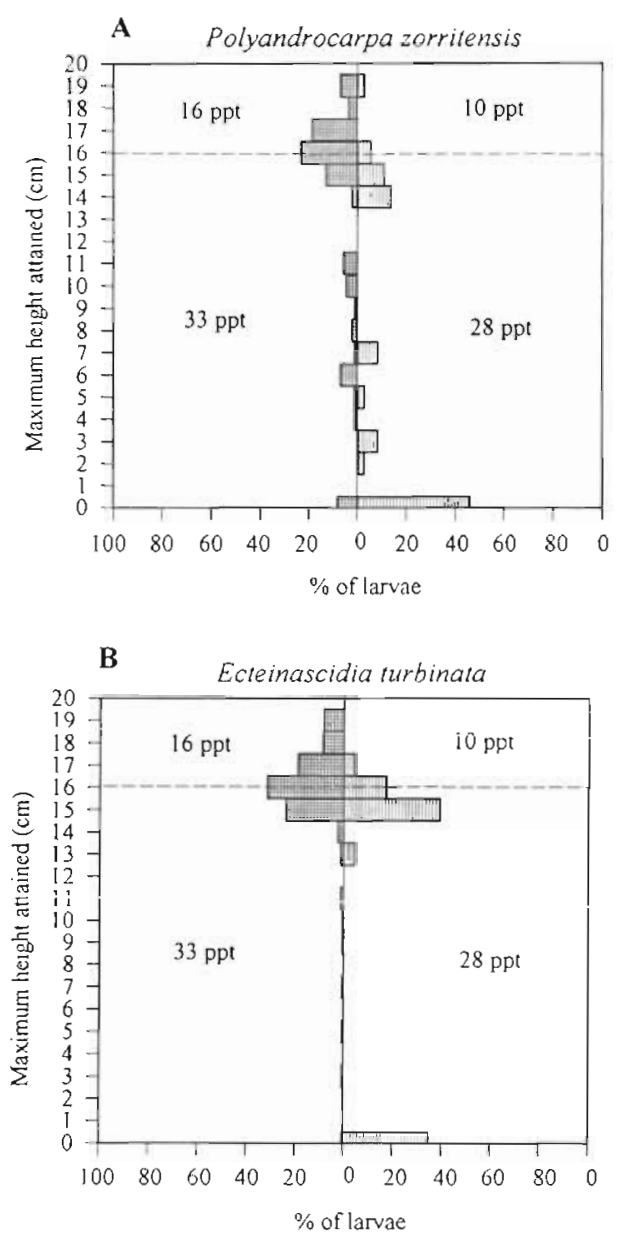

Fig. 7. Distributions of heights attained by vertically swimming larvae of Polyandrocarpa zorritensis and Ecteinascidia turbinata in stratified columns having similar salinity changes but bottom waters of different salinities

into the water column at all. Of those that did swim, most stopped either long before the halocline or as soon as they encountered the very lowest part of the halocline (Fig. 7A). E. turbinata tadpoles demonstrated a similar pattern of behavior (Fig $7 B$ ). The salinity difference between 28 and 10 ppt is approximately the same as the difference between 33 and $16 \mathrm{ppt}$, so if the change in salinity controls the response to haloclines, one would expect similar distributions in these 2 sets of experiments. However, the 16 ppt experiments with 33 ppt bottom water showed the same pattern as the $10 \mathrm{ppt}$ experiments with 33 ppt bottom water (Fig. 7) and a very different pattern from the experiments with 28 ppt bottom water and the same change in salinity. This indicates that the absolute salinities of the water above and below the halocline may in some cases be more important in determining behavior than the change in salinity.

\section{Larval behavior in unstratified water columns at low salinities}

The experiments with $28 \mathrm{ppt}$ water and the responses of larvae to low salinity layers above haloclines suggested that we might see differences in swimming activity in unstratified waters of low salinity. We tested this with larvae of Ecteinascidia turbinata and Polyandrocarpa zorritensis adapted to 33, 26, 22, and $16 \mathrm{ppt}$, prior to the experiments (Fig. 8A, B). Both species swam actively to the surface in $33 \mathrm{ppt}$ seawater, but remained for the most part on the bottom of the column at all lower salinities tested (Fig. 8A, B).

\section{DISCUSSION}

Several authors have documented stereotyped avoidance responses of marine invertebrate larvae to salinity discontinuities and have identified the critical salinity difference that elicits the behaviors (Turner \& George 1955, Lance 1962, Lyster 1965, Scarratt \&
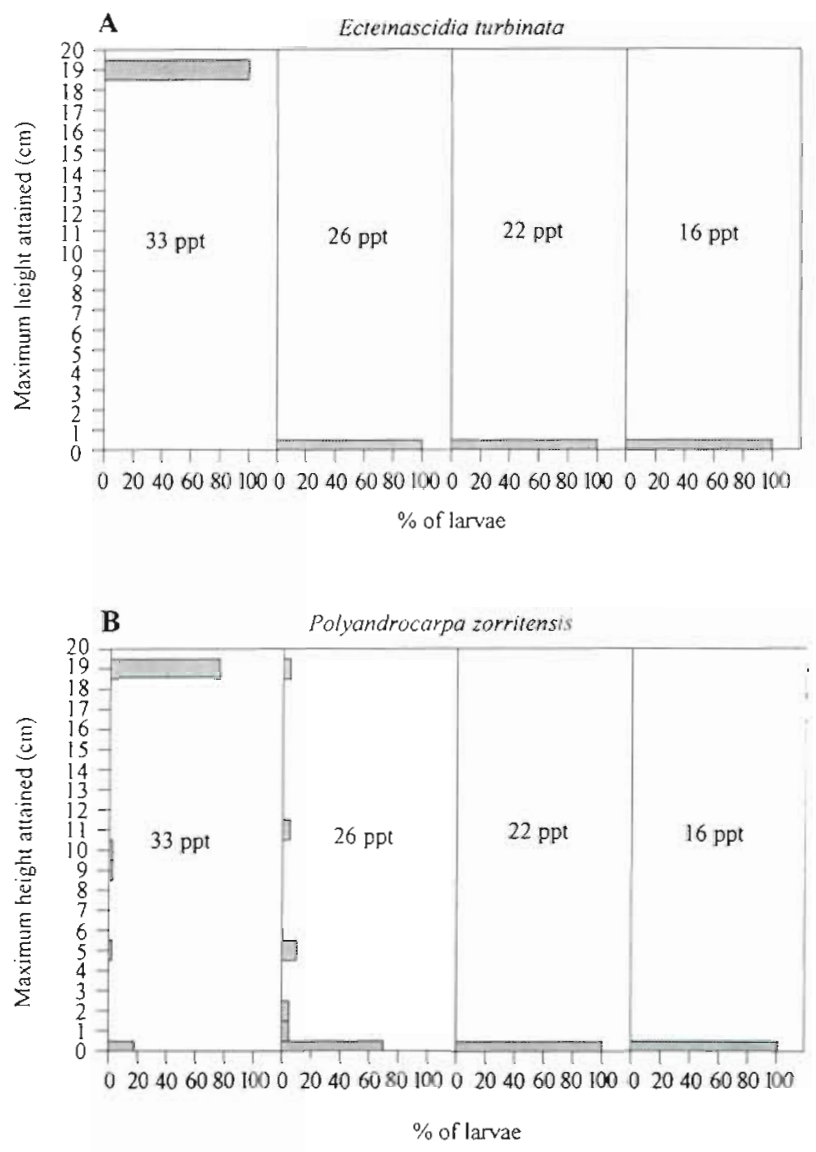

Fig. 8. Maximum heights attained by vertically swimming larvae of Polyandrocarpa zorritensis and Ecteinascidia turbinata in unstratified columns of 4 different salinities 
Raine 1967, Harder 1968). The larvae of various crustaceans, including lobsters (Homarus), anomuran crabs (Porcellana) and hermit crabs (Pagurus), generally avoid swimming into a layer of low salinity even if they are capable of doing so (Lance 1962, Scarratt \& Raine 1967, Roberts 1971). The ascidian larvae we studied showed predictable avoidance responses to haloclines at and below a critical salinity of $22 \mathrm{ppt}$ and more subtle behaviors in response to higher salinities. Larvae generally avoided low salinities by cessation of swimming followed by passive sinking into high salinity bottom water One species, Eudistoma hepaticum, swam down actively instead of sinking and another, $E$. olivaceum, sometimes swam in circles just below the halocline.

The 4 species we studied belong to 3 different families of ascidians, but demonstrated very similar responses in unstratified water of low salinity. In water of $33 \mathrm{ppt}$, larvae of all 4 species were very active and swam upward probably in response to gravity, ultimately concentrating at the surface. At all salinities below 28 ppt, there were always behavioral changes, the most common being inhibition of swimming. Larvae held at low salinities became lethargic and spent most or all of their time resting on the bottom. We have shown in a separate study that low salinities are often lethal for the larvae and juveniles of these same species, and that metamorphic success depends on salinity (Vázquez \& Young unpubl.). When salinities lower than 26 ppt were encountered by swimming larvae in a stratified water column, the majority of larvae stopped swimming and sank back into the high salinity bottom water. Even those few larvae that proceeded through the halocline toward the surface generally hesitated before continuing, then changed to a more erratic swimming pattern as they passed beyond the layer. Those that reached the surface by swimming through water of salinities lower than 26 ppt generally sank or swam out of the low salinity layer rather than remaining at the surface.

We expected species-specific differences in the responses of larvae to low salinity because 2 of the species we examined (Eudistoma olivaceum, Ecteinascidia turbinata) penetrate well into estuarine waters of variable salinity, whereas the other 2 species occur either in coastal habitats with full oceanic salinity or near inlets where regular influx of oceanic water dampens the salinity fluctuations. Although interspecific differences were noted, horizontal distributions are not adequately explained by salinity alone. All 4 species easily swam from $33 \mathrm{ppt}$ water into $26 \mathrm{ppt}$ water. At $22 \mathrm{ppt}$, the only species whose larval distribution was not affected by the halocline was a non-estuarine species, Eudisomta hepaticum. If salinity were the most important limiting factor, this species should extend further into estuaries than the other species. It does not. As a large encrusting species, perhaps it is limited by substratum availability instead.

We did find subtle species differences at $26 \mathrm{ppt}$ that could have distributional importance. Larvae of all species penetrated haloclines at 26 ppt, but only Eudisomta olivaceum larvae swam for extended periods of time at this salinity. The other species avoided prolonged residence above the 26 ppt halocline by sinking or swimming downward immediately after reaching the surface. This unique behavioral trait of $E$. olivaceum seems to correspond with the adult distributions; E. olivaceum is much more common in estuarine conditions of variable salinity than any of the other species studied. However this apparent cause-effect relationship between the behavior and distribution breaks down where the other species are concerned. For example, larvae of Ecteinascidia turbinata, adults of which are found in the same habitats (though much more rarely) as E. olivaceum, depart surface waters much more quickly than those of Polyandrocarpa zorritensis, adults of which almost never penetrate estuaries. Clearly other factors besides larval responses to salinity must be important in determining the horizontal distribution of adults. It would be useful to study the physiological tolerances of larvae and other life history stages to a range of salinities in order to determine if there are species-specific differences that we were unable to resolve in this study. Such a study should focus on salinities above $25 \mathrm{ppt}$ and test numerous small intervals in this range.

Crustacean larvae often respond to haloclines by a hop-and-sink behavior (they sink when encountering the halocline, but rise again after a very short period). This behavior may explain the tendency of many crustacean larvae to be concentrated at the halocline in field samples (Hansen 1951, Harder 1968). By contrast, compound ascidian larvae sink for a much longer period of time, so they do not tend to concentrate at the bottom of the halocline. The only ascidian larvae that are suspected of concentrating at a halocline are those of the solitary ascidian Ascidiella aspersa in a Swedish fjord (Young \& Svane unpubl.). This species has floating eggs which come to rest within the halocline layer at the same level as the highest adult densities found on the walls of the fjord.

In a typical stratified estuary on the east coast of North America, an upper layer of low-salinity water flows toward the mouth, while high-salinity bottom water has a net upstream flow (Pritchard 1967, Beardsley \& Boicourt 1980). Many workers have discussed how larval behavior might interact with the stratification and circulation patterns in estuaries to retain larvae near suitable adult habitats for settlement (e.g. Bousfield 1955, Wood \& Hargis 1971, Hughes \& 
Richard 1973). One commonly cited paradigm depends on the ability of larvae to stay within the high-salinity bottom water moving upstream. The behaviors we have observed in ascidian larvae could function in retention by keeping larvae within the high salinity waters that are not flowing out of the system. These halocline avoidance behaviors could be reinforced by negative phototaxis in the terminal stages (reviewed by Svane \& Young 1989) and by the very short larval lives that are characteristic of all compound ascidians.

Acknowledgements. We are indebted to Dr Suki Ekaratne, University of Colombo, for valuable comments and assistance in the experimental design. This study was supported by a postdoctoral fellowship from the Consellena de Educacion e Ordenacion Universitaria, Xunta de Galicia to E. Vázquez. This is Harbor Branch Contribution Number 1105.

\section{LITERATURE CITED}

Angel MV (1968) The thermocline as an ecological boundary Sarsia 34:299-312

Danse K (1964) On the vertical distribution of zooplankton in the sea. Prog Oceanogr 2:53-1.25

Beardsley RC, Boicourt WC (1980) On estuarme and continental shelf circulation in the Middle Atlantic Bight. In: Warren BA, Wunsch C (eds) MIT Press, Cambridge, MA, p $198-233$

Bingham BL (1990) The ecology of epifaunal communities on prop roots of the red mangrove, Rhizophora mangle. PhD dissertation, Florida State University, Tallahassee

Bousfield EL (1955) Ecological control of the occurrence of barnacles in the Miramichi Estuary. NatI Mus Can Bull Biol Ser 137: 1-65

Dybern BI (1967) The distribution and salinity tolerance of Ciona intestinalis (L.) f. typica with special reference to the waters around southern Scandinavia. Ophelia 4:207-226

Fransz HG, Miguel JC, Gonzalez SR (1984) Mesozooplankton composition, biomass and vertical distribution, and copepod production in the stratified central North Sea. Neth J Sea Res 18:82-96

Hansen KV (1951) On the diurnal migration of zooplankton in relationship to the discontinuity layer. J Cons Perm Int Explor Mer 17:231-241

Harder W (1968) Reaction of plankton organisms to water stratification. Limnol Oceanogr 13:156-168

Hughes DA, Richard JD (1973) Some current-directed movements of Macrobrachium acanthurus (Weigmann, 1836) (Decapoda, Palaemonidae) under laboratory conditions. Ecology 54:927-929

This article was presented by J. D. Gage (Senior Editorial Advisor), Oban, UK
Kendall AW Jr, Naplin NA (1981) Diel-depth distribution of summer ichthyoplankton in the middle Atlantic bight. Fish Bull US 79:205-226

Kinne O (1966) Physiological aspects of animal life in estuaries with special reference to salinity. Neth J Sea Res 3: $222-244$

Kinne $O$ (ed) (1971) Marine ecology. A comprehensive, integrated treatise on life in oceans and coastal waters, $\mathrm{Vol} \mathrm{I}_{\text {, }}$ Environmental factors, Part 2. Wiley-Interscuence, London, p $820-995$

Lance J (1962) Effects of water of reduced salinity on the vertical migration of zooplankton. J Mar Biol Ass UK 42:131-154

Lasker R (1975) Field criteria for survival of anchovy larvae. the relation between inshore chlorophyll maximum layers and successful first feeding. Fish Bull US 73:453-462

Lyster IHJ (1965) The salinity tolerance of polychaete larvae $\mathrm{J}$ Anim Ecol 34:517-527

Millero FJ (1993) What is PSU? Oceanography 6:67

McConnaughey RA, Sulkin. SD (1984) Measuring the effects of thermoclines on the vertical migration of the larvae of Callinectes sapidus (Brachiura: Portunidae) in the laboratory. Mar Biol 81:139-145

Nielsen $T G$, Lokkegaard $B$, Richardsun $K$, Pedersen FB. Hansen L (1993) Structure of plankton communnities in the Dosser Bank area (North Sea) during a stratified situation. Mar Ecol Prog Ser 95:115-131

Pritchard DW (1967) Observations of circulation in coastal plain estuanes. In: Lauff Gri (tedj Estuâries. Publ No. 83, Am Assoc Adv Sci, Washington, DC, p 37-44

Roberts MH Jr (1971) Larval development of Pagurus longicarpus (Say) reared in the laboratory. III. Behavioral responses to salinity discontinuities. Biol Bull 146:67-77

Scarratt DJ, Raine GE (1967) Avoidance of low salinity by newly hatched lobster larvae. J Fish Res Bd Can 24: $1403-1406$

Sokal RR, Rohlf FJ (1981) Biometry, 2nd edn. WH Freeman and Company, New York

Southward AJ, Barrett RC (1983) Observations on the vertical distribution of zooplankton, including post-larval teleosts, off Plymouth in the presence of a thermocline and a chlorophyll-dense layer. J Plankton Res 5:599-618

Svane I, Young CM (1989) The ecology and behaviour of ascidian larvae. Oceanogr Mar Biol A Rev 27:45-90

Turner HJ Jr, George CJ (1955) Some aspects of the behavior of the quahaug Venus mercenaria during the early stages. Rep Invest Shellf, Mass Dept Nat Res, Div Mar Fish 8:5-14

Williams R (1985) Vertical distribution of Calanus finmarchicus and $C$. helgolandicus in relation to the development of the seasonal thermocline in the Celtic Sea. Mar Biol 86: $145-149$

Wood L, Hargis WJ Jr (1971) Transport of bivalve larvae in a tidal estuary. In: Crisp DJ (ed) Fourth European marine biology symposium. Cambridge Univ. Press, Cambridge, p $29-43$

Manuscript first received: March 28, 1995

Revised version accepted: September 15, 1995 